\title{
Hidden treasures
}

\author{
In many cases, national laboratories and research centres do great research. But with no \\ common measure of performance and a lack of public awareness, do we fully recognise \\ their value?
}

Even the general public is somewhat aware of the big national labs in the United States. Indeed, abbreviations such as LANL, ORNL or LLNL are familiar to most with a basic scientific education. Overseen by the Department of Energy (DOE), the 21 US National Laboratories and Technology Centers receive more than 9.5 billion US\$ in funding from the DOE and currently employ a total of about 30,000 employees ${ }^{1}$.

This public recognition of the national labs originates largely from their historic origins: Oak Ridge and Los Alamos were the first ones - founded in 1943 as part of the Manhattan Project to build the atomic bomb. It is this role, as well as their involvement in high-profile projects such as the Strategic Defence Initiative of the Reagan era and their continuing scientific excellence, that led to the public awareness of 'US National Labs'.

Although the lack of data makes comparisons difficult, many large research institutions elsewhere seem to be less successful in terms of international visibility. In Germany, about half of the research budget goes to extrauniversity research. Many have heard of the Max Planck Society. However, not many will know that with an annual budget of 2.3 billion euros and almost 26,000 employees, the largest German research organization is the Helmholtz Association ${ }^{2}$, which runs the country's largest research centres.

Physicists will know the GSI in Darmstadt, where many of the transuranium elements were discovered, or the particle accelerator DESY in

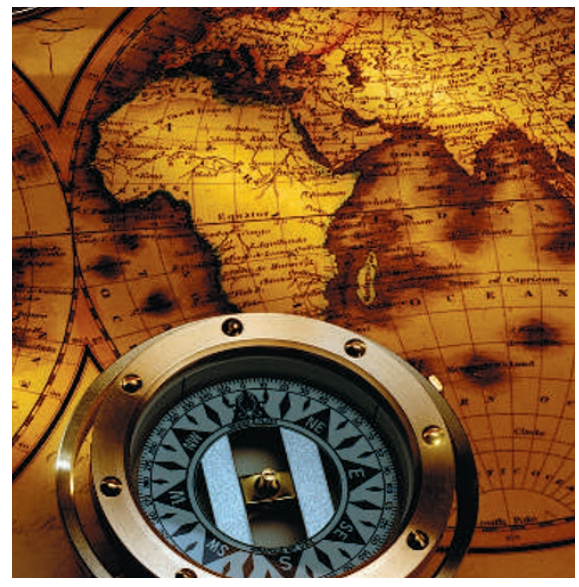

the host university. In such cases, when scientific breakthroughs hit the news, an outsider will have difficulty distinguishing between achievements of the CNRS or the university - the role of the CNRS is easily misunderstood. As for universities, such joint achievements typically do not enter university league tables, and are not represented appropriately.

A good example of increasing brand recognition is Japan's RIKEN. Founded in 1913, the institute now has about 3,100 employees and a budget of about 88 billion yen (750 million US\$). With activities such as open houses, public lectures and a freely available newsletter of research highlights ${ }^{4}$, RIKEN is actively increasing public awareness and thus strengthening its brand.

It seems that in many institutions

Hamburg. Materials scientists might know the research centres in Karlsruhe and Jülich. However, most people don't realize that they all are part of the Helmholtz Association, which has existed in this legal form only since 2001 . This lack of visibility is also obvious from the interview that we conducted with the president of the association, Jürgen Mlynek (page 323 of this issue $\mathrm{e}^{3}$. He readily admits there is a problem and that more needs to be done. For a common identity to be achieved, Mlynek's drive to establish a more visible use of 'Helmholtz' in the institute names would be a first step.

However, others do not necessarily fare better. A rather complex pattern exists in France with the CNRS. In an attempt to help French research, CNRS has, since 1966, created mixed research labs located at university campuses and jointly administrated by the CNRS and there is a lack of basic understanding of the importance of communication and interaction with the broader public. Excellent research is of course a prerequisite, but complementary attempts at raising public awareness should not be seen as a vain undertaking. Language might be an issue, but research is competing on an international level. For example, a strong global identity is key to attracting talented young researchers as well as external research funding. And finally, it is public tax money that finances most of these institutions and therefore the public should be provided, as much as possible, with access to key achievements.

\footnotetext{
References

1. www.doe.gov/about/budget.htm

2. www.helmholtz.de

Interview. Nature Mater. 6, 323-324 (2007)

4. www.rikenresearch.riken.jp
} 